Speakers bureau: Novartis, Pfizer, Roche, GSK, SOBI, Elena Baldissera Speakers bureau: Novartis, Pfizer, Roche, Alpha Sigma, Sanofi, Filippo Crimì: None declared, Pietro Zucchetta: None declared, Diego Cecchin: None declared, Maria Picchio: None declared, Lorenzo Dagna Grant/research support from: Abbvie, BMS, Celgene, Janssen, MSD, Mundipharma Pharmaceuticals, Novartis, Pfizer, Roche, SG, SOBI, Consultant of: Abbvie, Amgen, Biogen, BMS, Celltrion, Novartis, Pfizer, Roche, SG, and SOBI, Andrea Doria Consultant of: GSK, Pfizer, Abbvie, Novartis, Ely Lilly, Speakers bureau: UCB pharma, GSK, Pfizer, Janssen, Abbvie, Novartis, Ely Lilly, BMS, Franco Schiavon: None declared

DOI: 10.1136/annrheumdis-2020-eular.6478

\begin{tabular}{|l|l}
\hline FRI0215 & RESPONSE TO TOCILIZUMAB IN LARGE VESSEL \\
VASCULITIS ACCORDING TO THE EXTENT OF \\
BASELINE 18F-FDG VASCULAR UPTAKE
\end{tabular}

D. Prieto-Peña ${ }^{1}$, M. Calderón-Goercke ${ }^{1}$, I. Martínez-Rodríguez ${ }^{1}$, J. I. Banzo ${ }^{1}$, P. Vicente-Gómez ${ }^{1}$, J. García-Fernández ${ }^{1}$, M. A. González-Gay ${ }^{1}$, R. Blanco' ${ }^{1}$. ${ }^{1}$ Marqués de Valdecilla University Hospital, Santander, Spain

Background: ${ }^{18} \mathrm{~F}-\mathrm{FDG}$ PET/CT is useful to establish the presence and extent of large vessel vasculitis (LVV)(1-2). Early therapy is needed to prevent severe complications. Tocilizumab (TCZ) has shown efficacy in LVV (3-5). However, it is unknown if the extent of FDG vascular uptake may influence on clinical response to TCZ Objectives: To assess the correlation of the extent of baseline FDG vascular uptake in PET/CT scan with clinical response to TCZ in patients with LVV.

Methods: Single center study of patients with LVV treated with TCZ who were divided into 2 groups depending on the extent of vascular uptake in baseline PET/CT scan: a) 1-2 affected areas b) $\geq$ affected 3 areas. Vascular uptake was qualitatively assessed by two experienced nuclear medicine physicians in five areas (supraaortic trunks, thoracic aorta, abdominal aorta, iliac and femorotibial arteries). We assessed clinical improvement (no improvement/partial/complete), normalization of CRP $(\leq 0.5 \mathrm{mg} / \mathrm{dL})$ and/or ESR $\left(\leq 20 \mathrm{~mm} / 1^{\text {st }} \mathrm{h}\right)$ and reduction of prednisone dose ( $\mathrm{mg} /$ day).

Results: 30 patients $(24 \mathrm{w} / 6 \mathrm{~m})$; mean age $65.3 \pm 10.6 \mathrm{yrs}$. In baseline PET/CT, vascular uptake was observed in 1 or 2 areas $(n=13)$ and in $\geq 3$ areas $(n=17)$. There was a trend to higher ESR/CRP and shorter evolution of clinical symptoms before TCZ onset in patients with $\geq 3$ affected areas (TABLE 1). Clinical/ serological evolution and reduction of prednisone dose is shown in TABLE 2. No statistical differences were found. However, patients with $\geq 3$ affected areas tended to experience a slower clinical response.

TABLE 1.

\begin{tabular}{lccc}
\hline & $\begin{array}{c}\text { 1-2 vascular affected } \\
\text { areas }(\mathbf{n}=\mathbf{1 3})\end{array}$ & $\begin{array}{c}\geq 3 \text { vascular affected } \\
\text { areas }(\mathbf{n}=17)\end{array}$ & $\mathbf{P}$ \\
\hline Demographic data & & & \\
Age, mean \pm SD & $66.0 \pm 10.8$ & $64.8 \pm 10.7$ & 0.77 \\
Sex (women), $n$ (\%) & $11(84.6)$ & $13(76.5)$ & 0.67 \\
Evolution time before TCZ (months), & $26.0[3.5-34.0]$ & $5.0[1.5-10.0]$ & 0.02 \\
$\quad$ median [IQR] & & & \\
Laboratory markers & $30.0 \pm 27.3$ & $34.8 \pm 27.6$ & 0.64 \\
ESR (mm/1st $\mathrm{h})$, mean $\pm S D$ & $1.3 \pm 1.2$ & $1.8 \pm 1.7$ & 0.28 \\
CRP (mg/dL), mean \pm SD & & & \\
Previous treatment & $9.4 \pm 6.2$ & $7.9 \pm 6.9$ & 0.53 \\
Prednisone dose (mg/day), mean $\pm S D$ & $10(76.9)$ & $11(64.7)$ & 0.47 \\
TCZ therapy & $6(46.2)$ & $8(47.1)$ & 0.96 \\
Intravenous, $\mathrm{n}(\%)$ & & & \\
Combined with MTX, $\mathrm{n}(\%)$ & & &
\end{tabular}

TABLE 2.

\begin{tabular}{lccc}
\hline & $\begin{array}{c}\mathbf{1 - 2} \text { vascular } \\
\text { affected areas } \\
(\mathbf{n}=13)\end{array}$ & $\begin{array}{c}\geq 3 \text { vascular affected } \mathbf{P} \\
\text { areas }(\mathbf{n}=17)\end{array}$ & \\
\hline Complete clinical improvement, $n / N(\%)$ & & & \\
$6 \mathrm{~m}$ & $11 / 13(84.6)$ & $12 / 17(70.6)$ & 0.43 \\
$12 \mathrm{~m}$ & $12 / 13(92.3)$ & $13 / 17(76.5)$ & 0.36 \\
$18 \mathrm{~m}$ & $10 / 11(90.9)$ & $11 / 12(91.7)$ & 0.99 \\
$24 \mathrm{~m}$ & $8 / 8(100)$ & $9 / 10(90.0)$ & 0.99 \\
Normalization of ESR and/or CRP, $n / N(\%)$ & & & \\
$6 \mathrm{~m}$ & $13 / 13(100)$ & $16 / 17(94.1)$ & 0.99 \\
$12 \mathrm{~m}$ & $13 / 13(100)$ & $16 / 17(94.1)$ & 0.99 \\
$18 \mathrm{~m}$ & $11 / 11(100)$ & $11 / 12(91.7)$ & 0.99 \\
$24 \mathrm{~m}$ & $8 / 8(100)$ & $10 / 10(100)$ & 0.99 \\
Dose of Prednisone (mg/day), median [IQR] & & & \\
$6 \mathrm{~m}$ & $5.0[1.3-5.0]$ & $5.0[0.0-5.0]$ & 0.98 \\
$12 \mathrm{~m}$ & $2.5[0.0-3.8]$ & $0.0[0.0-5.0]$ & 0.97 \\
$18 \mathrm{~m}$ & $0.0[0.0-2.5]$ & $0.0[0.0-1.9]$ & 0.72 \\
$24 \mathrm{~m}$ & $0.0[0.0-2.2]$ & $0.0[0.0-2.5]$ & 0.77 \\
\hline & & & \\
\hline
\end{tabular}

Conclusion: TCZ therapy was effective in patients with LVV regardless the extent of FDG vascular uptake in baseline PET/CT scan. However, a trend to a slower clinical response was observed in patients with $\geq 3$ affected areas. References:

[1] Martínez-Rodríguez et al. (18)F-FDG PET/CT in the follow-up of large-vessel vasculitis: A study of 37 consecutive patients. Semin Arthritis Rheum.2018 Feb;47(4):530-537. doi: 10.1016/j.semarthrit.2017.08.009.

[2] Loricera et al. Non-infectious aortitis: a report of 32 cases from a single tertiary centre in a 4-year period and literature review. Clin Exp Rheumatol. 2015 Mar-Apr; 33(2 Suppl 89): S-19-31

[3] Calderón-Goercke $M$ et al. Tocilizumab in giant cell arteritis. Observational, open-label multicenter study of 134 patients in clinical practice. Semin Arthritis Rheum. 2019 Aug; 49(1):126-135. doi: 10.1016/j. semarthrit.2019.01.003

[4] González-Gay MA et al. Current and emerging diagnosis tools and therapeutics for giant cell arteritis. Expert Rev Clin Immunol. 2018 Jul;14(7):593605. doi: 10.1080/1744666X.2018.1485491.

[5] Loricera et al. Tocilizumab in patients with Takayasu arteritis: a retrospective study and literature review. Clin Exp Rheumatol. 2016 May-Jun;34(3 Suppl 97): S44-53.

Disclosure of Interests: D. Prieto-Peña: None declared, Monica CalderónGoercke: None declared, Isabel Martínez-Rodríguez: None declared, Jose Ignacio Banzo: None declared, Patricia Vicente-Gómez: None declared, Javier García-Fernández: None declared, Miguel A González-Gay Grant/research support from: Pfizer, Abbvie, MSD, Speakers bureau: Pfizer, Abbvie, MSD, Ricardo Blanco Grant/research support from: AbbVie, MSD, Roche, Consultant of: Abbvie, Eli Lilly, Pfizer, Roche, Bristol-Myers, Janssen, UCB Pharma and MSD, Speakers bureau: Abbvie, Eli Lilly, Pfizer, Roche, Bristol-Myers, Janssen, UCB Pharma. MSD

DOI: 10.1136/annrheumdis-2020-eular.1624

\section{FRI0216 STEROID SPARING EFFECT, LOWER INCIDENCE OF DISEASE RELAPSE AND DIABETES IN GIANT CELL ARTERITIS TREATED WITH IMMUNOSUPPRESSORS AB INITIO OR VERY EARLY: A MULTICENTER RETROSPECTIVE CASE-CONTROL STUDY}

L. Quartuccio ${ }^{1}$, M. Isola ${ }^{2}$, D. Bruno ${ }^{3}$, E. Treppo ${ }^{1}$, L. Gigante ${ }^{3}$, F. Angelotti ${ }^{4}$, R. Capecchi ${ }^{4}$, G. Vitiello ${ }^{5}$, E. Cavallaro ${ }^{1}$, A. Tavoni ${ }^{4}$, S. L. Bosello ${ }^{6}$, D. Cammelli ${ }^{5}$ S. De Vita ${ }^{1}$, E. Gremese ${ }^{3,6}$. ${ }^{1}$ Department of Medical Area, Rheumatology Clinic, Udine Academic Hospital "Santa Maria della Misericordia", Udine, Italy, Udine, Italy; ${ }^{2}$ Department of Medicine, Institute of Statistics, University of Udine, Udine, Italy, Udine, Italy; ${ }^{3}$ Rheumatology Unit, Catholic University of the Sacred Heart, Rome, Italy, Rome, Italy; ${ }^{4}$ Department of Internal Medicine, Clinic of Immunology, Pisa, Italy, Pisa, Italy; ${ }^{5}$ University of Florence, Florence, Italy; ${ }^{6}$ Division of Rheumatology, Fondazione Policlinico Universitario A. GemelliIRCCS, Rome, Italy, Rome, Italy

Background: Glucocorticoids (GC) are associated with serious side effects in giant cell arteritis (GCA). Immunosuppressive therapies (IT) gave conflicting results in GCA, regarding GC sparing effect. Recently, tocilizumab by blocking IL-6, has been licensed as first biologic treatment for GCA, being clinically effective and saving GC (1).

Objectives: To evaluate the usefulness of IT for GCA in: 1) minimizing the rate of GC-induced adverse events (AEs) and 2) reducing the risk of relapse.

Methods: A multicenter retrospective case-control study included 165 GCA was performed. The first group of patients (GCA-IT) included 114 patients who were treated with at least one IT given ab initio or within 3 months from the start of GC. The control group included 51 GCA who received only GC or an IT later than 3 months (GCA-steroid). The primary endpoints were the rate of GC-related side effects: infections, hospitalized infections, new onset systemic arterial hypertension, GC-induced diabetes and osteoporotic fractures.

Results: Methotrexate up to $20 \mathrm{mg} /$ week (138 patients), followed by cyclophosphamide (48 patients) and tocilizumab (27 patients) were the most frequently used IT. No difference was observed as concerns the follow-up time between the two groups [48.5 (IQR 26-72) vs 40 (IQR 24-69), $p=0,3$, rank-sum test)]. The two groups were similar as concerns sex $(p=0,13)$, while the first group $(69 \pm 8 \mathrm{yrs})$ was slightly younger than the second one $(72 \pm 7 \mathrm{yrs})(p=0,005)$. Comorbidity was similar between groups. Patients in the GCA-IT group showed a significant lower incidence of GC-induced diabetes (8/114, $7 \%$ vs $12 / 51,23,5 \% ; p=0,003$, chi-square test), while no differences were documented for rate of infections $(p=0,64)$, including hospitalized infections $(p=0,44)$, new onset systemic arterial hypertension $(p=0,68)$, or osteoporotic fractures $(p=0,32)$. Forty-four patients in the GCA-IT group (38,6\%), while 34 patients in the GCA-steroid group $(66,7 \%)$ experienced at least one relapse ( $p=0,001$, chi square test). There was no difference in terms of time to first relapse between the two groups $(p=0,53$, logrank test). GCA-IT group was exposed to lower dose of $G C$ at first $(p<0,0001$ 